\title{
LA CAIDA Y MUERTE DEL GRAN CONDESTABLE DE CASTILLA EN EL CONTEXTO DE LA LITERATURA DE SU EPOCA
}

Por

CESAR G. LOPEZ Scripps College

California 
La mañana del 2 de junio de 1453, los vecinos de Valladolid asistieron atónitos a uno de los sucesos más sorprendentes de la historia de Castilla: la decapitación del Condestable y Gran Maestre de Santiago, don Alvaro de Luna. Mientras que el lúgubre cortejo se abría paso desde la casa de Alonso de Estúniga, clonde se encontraba recluido, hasta la Plaza Mayor, don Alvaro, cabalgando sobre una mula, escuchaba las acusaciones del pregonero: "Esta es la justicia que manda hacer el Rey nuestro Señor a este cruel tirano e usurpador de la corona real: En pena de sus maldades mándale degollar por ello" (Crónicas 638) (1).

Momentos después, el seco golpe de la cuchilla rompía para siempre una relación que se había iniciado en 1410 , cuando Juan II tomó como

(1) Además de la Crónica de Juan II, la proclamación de la sentencia aparece recogicla en varios documentos (Cf. Round 152, nota 41). También los romances dan amplia cuenta tanto de la proclamación, como de los pormenores de la muerte de don Alvaro. El que lleva el número 38 en la colección de Pérez Gómez, que es la que utilizamos en este trabajo, dice:

Esta es la justicia, que manda hacer

al Condestable

de Castilla e! Rey,

por un delito

criminal y grave,

y es bien, que quien tal haze,

que tal pague. 
paje a don Alvaro de Luna. Tenía entonces el monarca la edad de cinco años, y don Alvaro andlaría rondando los dieciocho (Jaen 23) (2).

Descle este momento don Juan, que estaba dotado para las artes, pero no para el gobierno de un estado tan difícil como el de Castilla, no puclo ya vivir sin la compañía de don Alvaro, quien pronto se convirtió en su privado, llegando con el tiempo a ser la autoridad suprema del reino, por encima del propio soberano, sin que los intentos de los nobles por romper esta dependencia tuvieran nunca efecto, por lo que se dijo muchas veces que don Alvaro había embrujado al monarca (Crónicas 561-62; Round 41).

En el romance 39 tenemos:

$$
\begin{aligned}
& \text { Un miércoles de mañana } \\
& \text { a las nueve horas del clia } \\
& \text { sacan al gran condestable } \\
& \text { por Valladolid la villa } \\
& \text { con la voz del pregonero } \\
& \text { a grandes bozes dezía } \\
& \text { porque sea a todos notorio } \\
& \text { sepan questa es la justicia } \\
& \text { que manda hazer el rey } \\
& \text { a este hombre que aquí veis } \\
& \text { por usurpador tyrano } \\
& \text { que ha usado gran tyrania } \\
& \text { contra la nolule corona } \\
& \text { real, de nuestra Castilla } \\
& \text { mandan que sea degollado } \\
& \text { en pago de su malicia. }
\end{aligned}
$$

(2) El romance 26 recoge asi esta circunstancia:

Apenas tuve siete anos cle Aragón vine a Castilla, a servir al Rey don Iuan que ol segundos se dezía. Servile veynte $y$ seys anos los mejores de mi vicla, puso el ánimo en quererme grandes mercedes me hazia. 
Una de las armas más poderosas usadas contra el condestable por sus enemigos fue la literatura. El nombre de don Alvaro sería hoy conocido solamente por los eruditos de la historia si no fuera por la enorme cantidad de obras literarias que acerca de él se escribieron. Su subida espectacular y su muerte desastrosa lo convirtieron en un ejemplo viviente de caída de príncipes; su fama se eternizó en los romances, y su vida ocupó un lugar destacado en la producción dramática del Siglo de Oro, y luego en la del Romanticismo.

La poesía lírica castellana había iniciado su desarrollo con el advenimiento de los Trastámaras, y desde entonces había sido utilizada con fines políticos. Dentro de esta tradición, el nacimiento de Juan II dió motivo para una serie de poemas alegóricos que glorificaban al monarca, incrementándose la producción poética a lo largo de un reinado al que Puigmaigre calificó de verdadero pórtico del Renacimiento, y que contó con el Marqués de Santillana y Juan de Mena, dos de los grandes poetas del siglo XV (3). Es por ello lógico que el nombre de don Alvaro aparezca frecuentemente en boca de los poetas, tanto en poemas de circunstancias como en otros dedicados a glorificarlo, defenderlo o exigir su muerte. Sólo en el Cancionero de Baena hay 31 composiciones de Villasandino, y 6 del compilador, dedicadas directa o indirectamente a don Alvaro, y el número de romances sobre él conservados asciende a 58 , lo que sitúa al Condestable como el segundo personaje en importancia dentro del Romancero, inmediatamente después del Cid (Pérez Gómez 12).

Aunque el origen de la casa de Luna era aragonés, el abuelo de don Alvaro, Juan Martínez de Luna, había venido con otros caballeros arago-

(3) El conde de Puimaigre califica el reinado de Juan II de

...véritable renaissance où $I$ ' initiation simultanéc aux seuvres des anciens, des troubadours, des trouvères, des italiens, produisit une sorte $d$ ' enivrement qui $s$ ' empara de la nation entière. Tout le monde faisait des vers, évêques, grands scigneurs, chevaliers, marchands, artisans... $(\mathrm{I}, 20)$. 
neses a servir a Enrique II durante la guerra civil, quedándose afincado en Castilla. El padre del futuro Maestre fue don Alvaro de Luna, copero de Enrique III, y la madre una mujer de mala reputación, a la que llamaban la Cañeta. Precisamente a causa de este bajo origen, el padre del futuro Maestre nunca hizo ninguna provisión para este hijo quien, al quedar huérfano, gozó primero de la protección de su tío abuelo Benedicto XIII, el papa Luna, y luego de su tío don Pedro de Luna, arzobispo de Toledo, que fue quien lo presentó a Juan II. Ni el origen bastardo de don Alvaro ni la baja reputación de su madre fueron nunca un obstáculo para su triunfo en la corte, aunque con los años estos hechos fueran utilizados por sus enemigos para desprestigiarlo (4).

El plan de don Alvaro fue siempre el de someter a la nobleza, anular el poder político de las ciudades, e imponer una monarquía absoluta que dominara todos los estamentos, y cuyo gobierno radicara en un Consejo Real, elegido directamente por el monarca. La única manera de conseguir esto era mantener una aristocracia débil, y por ello don Alvaro procuró siempre alentar las ambiciones de la nobleza y fomentar la desunión de sus miembros, induciéndolos a enfrentamientos de los que él mismo resultaba siempre el principal beneficiado. Con razón diría Pérez de Guzmán, al hacer la semblanza de Juan II, que aen su tiempo fueron en Castilla tantas rebueltas e movimientos, e males dañosos y peligrosos, quantos no ovo en tiempo de los Reyes pasados por espacio de docientos años" (712).

El objetivo inmediato de la política de don Alvaro fue siempre destruir el poder de los primos del monarca, los famosos Infantes de Aragón, en

(4) Este Condestable don Alvaro de Luna alcançó tanto en Castilla, que no se falla por corónicas que hombre tanto alcançase, ny tan grande poderío toviese, ni tanto amado fuese de su Rey como él hera. Ca no era cosa en el rreyno que vacase c algo fuese que todo no venía a su mano, asi de lo seglar como de lo eclesiástico (Crónica del Halconero 176).

También Pedro de Fsquivas, en su Repertorio de Principes, dice de don Alvaro que era el mayor hombre sin corona que por entonces se fallaba. (Cf. Round capítulo 1). 
los que veía un gran peligro para la monarquía, a la vez que un obstáculo insalvable para imponer su sistema; a punto estuvo de conseguirlo en 1445, en la batalla de Olmedo, pero aunque entonces llegara el Condestable a la cumbre de su poder, consiguiendo el maestrazgo de Santiago, ya era demasiado tarde.

La tarea de don Alvaro fue un continuo tejer y destejer, en el que utilizó todos los hilos del entramado político, porque al carecer él mismo de las fuerzas suficientes para imponer su plan, tuvo siempre que apoyarse en alguna de las facciones en lucha. Por esta razón resulta sumamente difícil juzgar sus hechos, ya que los triunfos que obtuvo estuvieron siempre hipotecados a los intereses del grupo vencedor, lo que le impidió imponer totalmente sus ideas, obligándole a negociar. En cualquier caso puede asegurarse que ninguna persona en Castilla había gozado nunca de un poder tan absoluto como el que ejerció don Alvaro, quien controlaba todos los organismos del gobierno, de la administración, e incluso de la Iglesia (5).

(5) A medida que se aproximaba la caída del Condestable, arreciaron las críticas y acusaciones, insistiéndose en cómo el privado se había levantado por encima de todos los grandes linajes, olvidándose de la modestia que debía guardar por su bastardía y el bajo origen de su madre. En una carta enviada por los nobles al rey, y recogida en la Crónica del Halconero, se dice explicitamente que:

...el dicho Condestable, en su comien\%o, luego él se conosçió aver entrado en vuestra gracia, olvidando quien él hera, tentando a sobrado de vanagloria e sobervia e desordenada cobdiçia, presumió pujar todos los de vuestra casa, c después de grado sobre todos los grandes e nobles de vuestros rreynos (324).

También el cronista de Juan II, en el comentario que introduce la caída del Condestable, se pregunta que cómo fue posible que:

...un hombre espurio, nacido de tan baja madre... sin herencia, sin favor, sin otra mundana esperanza, en Reyno extraño... ser venido en tan grade estado... ser preferido $y$ antepuesto al todos los ilustres e grandes señores naturales cle España (691).

El Marqués de Santillana insistiria sobre el mismo punto en sus Coplas contra el Condestable.

O Luna, en quánto grado

tus principios son sabidos, y tu pobre y baxo estado por notorios son aviclos. 
No obstante, todo cuanto el Condestable gobernó y dispuso fue en nombre de su rey, por lo que, interpretando estrictamente los hechos, resulta que, en el reinado de Juan II, la monarquía alcanzó una autonomía muy superior a la que había tenido con los soberanos anteriores, siendo sólo comparable a la que tendría con los Reyes Católicos, a quienes don Alvaro señaló el camino (6).

Aunque la nobleza estuvo la mayor parte del tiempo combatiendo al monarca (al que tuvieron dos veces prisionero), oficialmente nunca se rebelaron contra Juan II, recurriendo al subterfugio de presentar estas acciones como encaminadas a liberar al soberano del poder del Conclestable, a quien acusaron de tiranía. Pérez de Guzmán afirma que la majestad real no sólo nunca estuvo en peligro, sino que en los momentos difíciles del reinado, en aquellos que hubo de capitular, fue siempre acatada y reverenciada por todos los magnates del reino (718). Esta es también la idea que expresa Juan de Mena en su Laberinto cuando al referirse al momento en que los nobles se apoderaron de la persona del monarca en Medina del Campo, dice:

Vi la furia çevil de Medina

e vi los sus muros non bien foradados:

vi despojadores e vi despojados

fechos acordes en paz muy aína;

vi que al su rey cada cual enclina

yelmo, cabeça, con el estandarte,

temiendo la justa real disçiplina (estrofa 155).

Es muy obvio, sin embargo, que todas estas acusaciones eran producto de la envidia, a la vez que una propaganda política, puesto que los bastardos cran plenamente aceptados y gozaban de todos los privilegios en una sociedad en la que hasta la dinastia reinante tenía ese origen.

(6) Esta autoriclad del monatca se pone bien de manifiesto en su relación con las Cortes; Juan II (es decir don Alvaro) utiliza los subsidios concedidos para la guerra de Granada en 1429 y en 1444 y 1445 , pese a lo cual las Cortes continuaron dándole al monarca cuanto este les pedía, a veces en cantidades tan grandes como los 80 millones concedidos en Toro en 1441. Fn 1430, los procuraclores reunidos en Salamanca, clespués de conceder los subsidios pedidos por el rey, le dijeron a este; .Se ha hecho todo lo que es ventajoso a vuestra alteza, anadiendo que estaban a su disposición todas las ciudades y villas que los habian elegicko por sus representantes" (Suárez 107, 117, 129, 172; Piskorski 156, 159). 
No es extraño por eso que, pese a la pusilanimidad de Juan II, poetas cortesanos, como Villasandino, presenten de él una imagen gloriosa:

D'este mundo el mayor

príncipe, muy excelente

Rey d'España suficiente

alto par de enperador (Baena 367).

Y Juan de Mena, en otro pasaje del Laberinto, lo llamará "César novelo," y "novel Augusto," afirmando que su fama sería superior a la de todos los monarcas que le precedieron:

Será rey de reyes, señor de señores, sobrando y venciendo los títulos todos, e las fazañas de reyes de godos, e rica memoria de los sus mayores (estrofa 271)

El protagonismo político de don Alvaro había comenzado en 1420 , cuando libertó a Juan II de manos del infante don Enrique, quien lo tenía secuestrado en Tordesillas. Desde ese momento, y hasta el final de su vida, don Alvaro sería combatido militar y políticamente por la nobleza partidaria de los Infantes de Aragón, es decir, por todos aquellos que se oponían a una monarquía totalitaria y luchaban por conservar unos privilegios de clase en un período en el que los ideales de la antigua caballería estaban llegando a su fin.

En la larga carrera política del Condestable hay dos momentos cruciales que dieron lugar a una abundante producción poética en la que concentramos nuestro análisis. El primero alcanza desde 1437 a 1445, período de continuas guerras civiles; el segundo gira alrededor de la muerte del privado, acaecida en 1453. 
En 1439, Juan de Navarra y el infante don Enrique, su hermano, que habían ido a Italia en 1430 huyendo de don Alvaro, regresaron a España, e inmediatamente tomaron parte en los conflictos internos de Castilla, consiguiendo en 1441 la condena y el segundo destierro del Condestable (el primero había sido en 1427), por seis años, siguiendo a este hecho el secuestro de Juan II en 1443 y, finalmente, la batalla de Olmedo en 1445, en la que el partido de los Infantes de Aragón fue derrotado, perdiendo la vida don Enrique, y llegando don Alvaro a la cumbre de su poder al conseguir el maestrazgo de Santiago (7).

Durante el primero de estos períodos, la actividad literaria corrió pareja con la militar, desarrollándose una intensa campaña para desprestigiar al de Luna y a su sistema de gobierno, al mismo tiempo que se ensalzaba a los nobles que luchaban junto a los infantes de Aragón. La Crónica de Juan II nos da amplias noticias de las cartas y embajadas que se cruzaron entre el soberano y la nobleza, así como de los manifiestos de ésta y las amenazas lanzadas contra el Condestable (Crónica 556-559) (8).

Juan de Dueñas, utilizando las profecías de Merlín, en un decir alegórico, que debió de escribirse hacia 1440, vaticinaba la caída de don Alvaro

(7) Entre 1428, fecha en que empezaron los conflictos, y 1430, en que se firmaron en Majano treguas por cinco años entre Castilla y Aragón, don Alvaro consiguió cambiar por completo el panorama político. No sólo conjuró el peligro de una invasión de Aragón, sino que destruyó también el poder político de los Infantes, desterrando a estos de Castilla, deshaciendo su partido, y consiguiendo reunir a la nobleza alrededor del monarca. La situación cambió en 1439. cuando Juan de Navarra y su hermano Enrique regresaron de Italia, tomando inmediatamente partido en los conflictos de Castilla, adhiriéndose a su bando la reina y el príncipe heredero, lo que trajo como consecuencia la condena de don Alvaro por un tribunal y su destierro. La inhabilidad política de Juan de Navarra y su clespotismo (llegó a apoderarse de la persona de Juan II, pensando quizás destronarlo), dieron lugar a un nuevo agrupamiento de la nobleæa y a la batalla de Olmedo, la más importante del reinado.

(8) En el conjunto de manifiestos y cartas que circularon en estos años, destaca una enviada a! rey por Juan de Valera, en la que le recuerda al soberano que su ineficacia, $y$ la actitud del privado, pueden llevar a una guerra civil desastrosa, en la que se corria el riesgo de que España fuera destruida (Crónica 573-74). En 1448, volvería a insistir solure el mismo tema (Crónica 559-60). 
y de su partido, al regresar de Italia Alfonso V de Aragón, regreso que determinaría la reconciliación de Juan II con sus primos los Infantes:

El sol sea claro, la Luna escuresca

con el circuito del çielo primero

e los otros siete, fastal postrimero,

pierdan las sus fuerças hasta que fallesca.

E el Aguila prima, questá por mudar, el año que viene aquende de Agosta, tienda sus alas por toda la costa desde Cartagena fasta Gibraltar.

E espere al León allá en Trafalgar, a donde serán concordes en una;

e entonces fará su clisi la Luna, e los nuevos cielos podrán alumbrar.

E desto verná el crudo castigo, e los merescientes aver mala fin; e las profecías del sabio Merlín farán su comienço, segund que vos digo (9).

Unos años después, el Marqués de Santillana exhortaba a los nobles en un soneto (XVII), a hablar menos y hacer más:

No en palabras ánimos gentiles, Non en menaças ni'n semblantes fieros

Se muestran altos, fuertes e viriles Bravos, audaces, duros, temederos.

Sean los actos non punto civiles, mas virtüosos e de cavalleros, e dexemos las armas femeniles, abominables a todos guerreros.

(9) Amador de los Rios, al citar este poema en su artículo -La poesía política en el siglo XV., se equivoca al suponer que Juan de Dueñas había regresado de Italia en 1436 , cuando en realidad todavía se encontraba alli en junio de 1439, según ha demostrado Vendrell Gallostra (83). Este decir debió de componerse en España entre 1440 y 1441. 
Es evidente que fue este uno de los momentos de mayor confusión política del reinado; el mismo Santillana vuelve a referirse a esta situación, con hondo pesimismo, tanto en su Lamentación de España, como en la Questión fecha a don Alonso de Cartagena, Obispo de Burgos, o el soneto XVIII, obras todas escritas también por estas fechas:

Oy, ¿qué diré de ti, triste emispherio?, ¡O patria mía!, ca veo del todo yr todas cosas ultra el recto modo, donde se espera immenso lazerio (XVIII).

Pero aunque todos eran conscientes de que las luchas civiles podrían llevar a la destrucción de España, como constantemente se repite, no todos estaban de acuerdo en que los males que los azotaban fueran una consecuencia de la mala administración del Condestable. Juan Alfonso de Baena, en uno de los decires más importantes de su producción poética, después de un análisis de la historia de España, comparaba a Castilla con un enfermo grave a quien sólo Dios, "el gran físico prudente," podía sanar, pero con la ayuda de un boticario muy certero que fuera capaz de aplicar la medicina, el cual no era otro que don Alvaro de Luna, de quien acto seguido hacía una gran apología:

Boticario muy çertero mucho cumple que se busque

por Castilla, e se rebusque muy fiel e verdadero; porque todo el bien entero del enfermo, su beuir, del sanar e del morir todo va en el espeçiero.

Por lo qual muy apurado deve ser tal ofiçial, e mas claro qu'el cristal 
para fecho tan granado;

e por ser bien atenprado

el xarope e non amargo,

señor, tome este cargo

el vuestro leal Privado (Baena 1209).

La defensa más importante que se hace del privado, tanto por la categoría del autor como por la del poema, es la de Juan de Mena, quien le dedicó 36 estrofas de su Laberinto, una obra cuyo contenido moral, como señaló Lapesa, se declaraba expresamente en la estrofa sexta: "Apolo / espira en mi boca porque pueda sólo / virtudes e viçios narrar de potentes". Mena no cita los nombres de los virtuosos próceres que vivían en su época, salvo el del "muy prepotente don Juan el segundo," a quien se ofrece el poema, y el de su privado:

Aquel cuyo ánimo, virtud e nombre tantas de partes le fazen de ombre quantas estado le da de señor, las quales le fazen ser mereçedor e fruto de mano de nuestro gran rey e clara esperiençia de su firme ley, e de la Fortuna jamás vençedor (estrofa 236).

Tampoco nombra Mena directamente a los nobles que creaban los problemas en Castilla, obviamente porque debería de tener miedo de alguna represalia, pero si da cuenta de los sucesos acaecidos en la catedral de Toledo, cuando el infante don Enrique hizo derribar y fundir una estatua de bronce del Condestable que éste había mandado construir para que adornase su sepulcro después de su muerte:

$\mathrm{Ca}$ un condestable armado, que sobre un gran bulto de oro estaba assentado, e todo desfecho fue tornado cobre (estrofa 265). 
Este hecho servía también a Mena para dar una explicación diferente a los rumores que por entonces circularon, y de los cuales él se hace eco en el poema, acerca de una bruja que había vaticinado el fin de don Alvaro:

E del condestable judgando su fecho así determino su fado e pregono: será retraído del sublime trono e aun a la fin del todo desfecho (estrofa 256).

Aunque la profecía se cumplió trágicamente años más tarde, Mena pudo decir en este momento que el vaticinio ya se había cumplido al destruirse la estatua, y si antes había presentado a don Alvaro cabalgando sobre la Fortuna y domando su cuello con ásperas riendas (estrofa 235), ahora lo podía presentar como su compañero inseparable:

Por ende, magnífico y grand condestable, la çiega Fortuna, que avía de vos fambre, farta la deja la forma de aranbre, de aquí adelante vos es favorable; pues todos notemos un caso mirable, e nótenlo quantos vinieren de nos, que de vos e de ella, e della e de vos nunca se parte ya paz amigable (estrofa 267) (10).

(10) Otra leyenda cuenta que un astrólogo había predicho a don Alvaro que moriría en Cadalso, e interpretando éste que se trataba de una de sus villas, cerca de Escalona, nunca más la visitó (Round 214). El romance 7 , recoge este augurio:

Setenta villas te ofrezco sólo me dexa a.Cadhalso, a donde morir entiendo, pues con fúnebres anuncios me predijo un Agorero, que moriría en cadahalso; quiera Dios que sea presto. 
La razón de esta defensa incondicional de don Alvaro por parte de los funcionarios reales hay que buscarla en el principio del reinado de los Trastámaras. Enrique II, que recelaba de los peligros que podían derivarse de una nobleza muy poderosa, había colmado a ésta de mercedes y títulos no hereditarios, pero había depositado el poder en una nueva clase de burócratas profesionales, los letrados, que demostraron siempre su lealtad a la monarquía, especialmente durante la minoría de Enrique III. En ellos se apoyó también don Alvaro para imponer su sistema; por eso es lógico que tanto Baena como Villasandino o Juan de Mena, funcionarios al servicio de la corona, defendieran la facción del monarca, lo que es tanto como decir la de su privado. En Villasandino o en Baena podrían verse además intereses personales, ya que los dos recurrieron numerosas veces a don Alvaro para pedirle mercedes, como atestigua el Cancionero de Baena. En el caso de Mena, sin embargo, no hay ninguna duda de que lo hacía por lealtad al privado y a la monarquía, ya que el poeta era el protegido del Marqués de Santillana, con quien mantuvo hasta la muerte una estrecha amistad, y este noble era uno de los peores enemigos de don Alvaro, aunque por conveniencia política apareciera a su lado en momentos decisivos para la corona, como en la batalla de Olmedo. Es interesante que mientras Santillana no recoge este hecho de armas en ninguno de sus poemas, pese a ser la batalla más importante del reinado, Juan de Mena lo utiliza para glorificar al débil de Juan II, a quien califica de urey plus quam perfecto,» y a quien se dirige en esto términos:

Rey virtud, Rey vencedor, principe nunca vencido, solo vos a quien, señor victoria dando rigor, clemencia fizo sofrido. Cesarea celsitud, superagusta colupna, dévos Dios mucha salut, pues nos da vuestra virtud tregua contra la Fortuna (Obra 179). 
Pareció, en efecto, que con esta victoria, que destruía el poder de los Infantes de Aragón y de sus partidarios (el propio don Enrique murió días después a consecuencia de las heridas), la paz volvería a Castilla. De la misma opinión era el autor anónimo de las coplas de iAy, panadera!:

Porque ya, Señor, siquiera

hayamos paz algún rato,

ca del dicho desbarato

a muchos quedó dentera (207).

En esta ocasión don Alvaro consiguió la gran ambición de toda su vida, el maestrazgo de Santiago, pero la situación política no cambió demasiado y, poco después, la nobleza, que seguía odiándolo, volvió a formar nuevas ligas. Lope de Estúñiga, que se encontraba preso por orden del Condestable, amenazaba a éste con la inestabilidad de la Fortuna y los cambios que podían producirse (Cancionero de Hernando del Castillo, f. 41):

E quien es más ensalçado ese está menos quïeto: que por vuestro mal pecado, pocas veçes gran estado viene a manos de viznieto. $\mathrm{E}$ con este sobresalto de trabajo e desçendida, ¿quién sosegará su vida, pues de quien sube más alto se espera mayor caída?

Si durante el primer período que acabamos de estudiar (1437-1445), los nobles se contentaban con el destierro de don Alvaro, en 1453 la única solución que les parecía viable era su muerte. Y, en efecto, don Alvaro fue detenido en Burgos el 3 de abril de 1453, siendo conducido a la forta- 
leza de Portillo y, después de un largo paréntesis, ejecutado en Valladolid, tras haber sido acusado por un tribunal de tiranía y de haber ocupado el lugar del monarca (11). Pero Guillén de Segovia, en un Dezir a la muerte de don Alvaro de Luna, recogía estos cargos:

Tres delitos le pusieron

gran crueza, tiranía, et al rey, segunt sintieron, ocupar la señoría (Amador 355).

La producción literaria que corresponde a este segundo período es la más abundante, girando principalmente alrededor del tópico de la muerte de don Alvaro y de las circunstancias que la acompañaron (12). Las coplas de origen popular son generalmente favorables al privado (que hasta cierto punto gozaba de simpatía entre el pueblo llano), atribuyendo su caída a la inestabilidad de los bienes de Fortuna, la envidia de los nobles, y la codicia y debilidad del monarca. Por otra parte, las composiciones que pertenecen a los poetas del bando contrario expresan no sólo la alegría de los vencedores, sino que también dejan ver el odio que la

(11) El tribunal no se atrevió nunca a dictar sentencia de muerte contra don Alvaro, por lo que este fue ejecutado como consecuencia de un mandato real (hecho que recogen muchos de los romances), dando lugar a que posteriormente se pusiera en entredicho la legalidad del procedimiento. (Cf. Round, capítulo 5).

(12) La subida espectacular de don Alvaro, y su trágica caída y muerte, fueron el tema de romances que, a su vez, inspiraron numerosas comedias. Pérez. Gómez cita una obra de Lope, La prueba de los amigos, en la que uno de los personajes dice:

\footnotetext{
¿Qué piensan estos poetas, pues que no hay semana alguna sin don Alvaro de Luna y otros cuarenta planetas? Romances de tres en tres a un enfadoso sujeto; mas como es luna, en efecto, sale nueva cada mes (37).
} 


\section{nobleza sentía por el Condestable, y que ahora, sin miedo a represalias, se manifiesta sin piedad (13). \\ Diego Valera increpaba así al privado:}

¿Qué fue de vuestro poder, grant Condestable de España, pues ningund arte nin maña non vos pudo sostener? (Amador 350).

De manera parecida se dirigía al Condestable, ya muerto, Johan de Valladolid, en un decir recogido por Pérez Gómez en la introducción a su Romancero:

(13) También hubieron poetas entre la nobleza que juzgaron los hechos con más imparcialiclad. El mismo Pero Guillén, ya mencionado, al referirse a la tiranía y crueldad de que se acusaba al Condestable, comentaba:

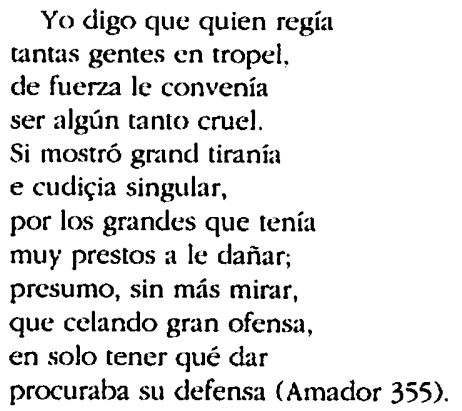

Y Pérez de Guzmán, de cuyo sentido momal no caben dudas, decía al hacer la semblanza del Condestable:

Ayudó a muchos con el rey e por su mano ovieron merçedes del rey e grandes benefiçios, e si fizo daño a muchos, también perdonó a muchos grandes yerros que le fizieron.

... E con esto fizo al Rey facer a muchos grandes esecuciones de prisiones y de destierros, e confiscaciones de bienes, e aun muertes, para lo cual hallaba asaz favores porque repartiendo entre los unos lo que tomaba a los otros, hallaba asaz ayudadores; ca la antigua e loable costumbre de los castellanos a tal punto es venida, que por haber el despojo de su pariente e amigo, le consentian prender o matar (716-17). 
Conde estable exclareçido

persona real extraña, mirad que enxiemplo y fazaña

es en poco acaesçido el gran pujante sobido, Maestre de Santiago, en çetro profundo lago, para siempre está perdido.

Esto a todos satisfaze, si bien lo quieren mirar, que por tiempo el que mal faze ha syn dubda de pagar.

Tirano, quería robar y mandar más que no el Rey; plugo a Dios y a buena ley deste mundo lo sacar (32).

No era menos cruel el autor de unas coplas anónimas, que increpaba de esta manera al privado después de muerto:

El tragón gusano coma

non al modo que solía, revese la glotonía;

non se farte de carcoma (Amador 352).

Pero sin duda es el Marqués de Santillana el escritor contemporáneo que de manera más sistemática, y con más profundidad, atacó a don Alvaro. Don Iñigo no sólo condenó los excesos del Condestable, sino que, en su Doctrinal, intentó también señalar las normas por las que debería regirse la figura política del privado en lo sucesivo, lo mismo que, en los Proverbios, había señalado al futuro Enrique IV cómo debería de ser la figura del principe, de acuerdo, claro está, con los deseos y aspiraciones de la clase noble. 
En el período comprendido entre la prisión del Condestable en Burgos, y su ejecución en Valladolid, Santillana dirigió a Juan II tres obras fundamentales: el Soneto XXX ("Venció Aníbal el conflicto de Canas), el poema Favor de Hércules contra Fortuna, y las Coplas contra el Condestable don Alvaro de Luna.

El soneto presenta el ejemplo de Aníbal, quien por dejar pasar demasiado tiempo, nunca llegó a conquistar Roma, incitando a Juan II a tomar acción inmediata contra el privado:

La graçïa leemos sea dada

a muchos, e a pocos la perseverança, pues cle los raros sed vos, rey prudente;

e non vos canse tan viril jornada, mas conseguidla toliendo tardança quanto es loable, bueno e diligente.

El poema Favor de Hércules, uno de los más complicados del Marqués, presenta de forma alegórica los crímenes cometidos por don Alvaro, y exige de Juan II la inmediata condena a muerte de aquel (14). Tanto el soneto como el poema están destinados a un público culto y restringido, y debieron de circular entre los miembros del Consejo Real que juzgaron a don Alvaro. Por el contrario, las Coplas pertenecen al tipo de sátira política cuya finalidad es comunicar un acontecimiento a un amplio auditorio. No hay por tanto, en éstas, referencias librescas ni tono culto, expresándose el autor de la manera más llana posible, utilizando el verso octosílabo que ayuda a la transmisión oral. La intención propagandística queda patente en el pareado inicial:

De tu resplandor, ¡Oh Luna! te ha privado la Fortuna.

(14) Estudio este poema extensamente en un libro que estoy preparando sobre el Marqués de Santillana. 
Siguen a continuación cuarenta y nueve coplas que constituyen el cuerpo de la composición, terminado en una semistrofa que hace de finida y que contrapesa el pareado inicial. La obra se estructura en dos partes, cada una de las cuales se divide internamente en tres momentos. En la primera, formada por 24 coplas, se cuenta la ascensión del Condestable (coplas 1 a 7), se enumeran los cargos contra él, como si se tratara de un proceso ( 8 a 17 ), y se da cuenta de su caída, justificando su prisión (18-24). En la segunda parte, formada por las 25 coplas restantes, más la finida, se pide a Dios (25 a 34), a la reina (35-43), y al príncipe (44-49) que ayuden al monarca a completar su obra y a gobernar dignamente a su pueblo.

La estructura de la obra contribuye a resaltar la función de la misma. De un lado se divulga los crímenes del Condestable y se crea un ambiente hostil que incite al castigo ejemplar y a la revancha; de otro, se fuerza al soberano a continuar por el camino iniciado, atrayendo al príncipe al bando real. Si en la primera parte se presenta a don Alvaro como figura diabólica, cuya soberbia sin límites le llevó a tiranizar al pueblo, despojar al monarca de todas sus prerrogativas y creerse invencible, en la segunda se insiste en el carácter religioso de la lucha, inspirada por Dios. La condena espiritual de don Alvaro exigía la del cuerpo, y ambas justificaban ante el pueblo la acción de los nobles rebeldes que, por más de 30 años, habían intentado destruir al privado.

Cuando ya el mandato real había acabado con la vida de don Alvaro, don Iñigo escribió el Doctrinal, el cual supera ampliamente a todos los Testamentos y Coplas que por entonces se compusieron con este motivo (15). Al estar compuestos por la misma mano, y sobre el mismo hecho, Coplas y Doctrinal presentan muchos puntos comunes. Ambos tienen apro-

(15) Diego de Torre compuso un Testamento del Maestre de Santiago, citado por Amador, en el que también don Alvaro se acusa de sus pecados y prepara su propia ejecución, pero la obra carece de la fuerza del Doctrinal de Santillana. 
ximadamente la misma extensión y están divididos en dos partes que se subdividen en tres núcleos. Usan la misma estrofa, el mismo verso y colocan las acusaciones en la primera parte, mientras en la segunda se da entrada al elemento religioso. También hay coincidencias en los temas $y$, sin embargo, se trata de dos obras completamente diferentes por su significado.

Escritas las Coplas en vida del privado, cuando todavía era posible un cambio en la actitud del monarca, éstas están concebidas como un panfleto de propaganda política que quiere impulsar el ánimo del rey con halagos. Pero, una vez conseguida su destrucción, era el momento de meditar y asimilar la enseñanza que se desprendía de aquella muerte. La desaparición de un personaje tan importante, y además en circunstancias tan indignas, debió de producir una conmoción profunda, incluso en los que habían instigado su muerte.

Se hacía entonces necesario presentar algún tipo de justificación que legalizara la situación en las ciudades, por lo que Juan II les envió una carta, que se ha supuesto fuera redactada por el Marqués (16). También había que acallar las conciencias, para lo que sirvió el Doctrinal. En él todavía se mantienen acusaciones contra el Condestable, lo cual era necesario para justificarse, pero el autor se sirve de ellas, lo mismo que de la confesión del privado, para presentar un ejemplo de las miserias humanas y de la pudredumbre del alma pecadora, advirtiendo a los futuros privados (y ya se perfilaba amenazadora la figura del Marqués de Villena), de la vanidad de los bienes del mundo y de los peligros que las riquezas y el poder encierran.

(16) En la carta se recogían todos los cargos que la nobleza habia presentado contra el privado desde 1440, guardando mucha semejanza con las acusaciones de Santillana en sus Coplas. Es interesante comparar esta carta, recogida en la Crónica de Juan // (684-691) con la enviada por la nobleza en 1440 (560), y con la que se incluye en la del Halconeno (320-333). El juicio y la conciena de don Alvaro levantaron muchas controversias legales, no sólo en su tiempo, sino muchos años después (Cf. Round, capítulos 3 y 4 ). 
El Doctrinal se apoya en dos temas que se desarrollan simultáneamente y cuyo fondo doctrinal se encuentra en los Proverbios: el de bien vivir y el del mal vivir, el del pecado y el de la virtud.

Utilizando el motivo del auri sacra fames, don Alvaro muestra la triste realidad: de todas sus riquezas lo único que le queda es el cadalso que le espera. Se trata por tanto de un ars vivendi, en el que se muestra los peligros a los que están expuestos, tanto los privados como las personas que se mueven en la corte, señalándose los medios para evitarlos. Pero es también un ars moriendi, porque a través del desprecio de los bienes del mundo, de la contricción, la penitencia, y la confesión, se consigue salvar el alma.

Después de declarar públicamente sus faltas, y de dibujar el nuevo tipo de privado que conviene al reino, viene la confesión. Con la absolución del Condestable, el Marqués de Santillana le abre a don Alvaro las puertas de la salvación eterna, pero le abre también las de la fama literaria, uniendo su nombre al de quien en vida había sido su enemigo irreconciliable. 


\section{BIBLIOGRAFIA}

AMADOR DE LOS RIOS. "La poesía política en el siglo XV", Revista de España. XXIV (1872): 337-364.

Baena, Juan Alfonso. Cancionero de Baena. Ed. José María Azáceta. 3 vols. Madrid: C.S.I.C., 1956.

Coplas de jAy, Panadera! en Poesía de protesta en la Edad Media castellana. Ed. Julio Rodríguez Puértolas. Madrid: Gredos, 1968.

Crónica de Juan II, en Crónicas de los Reyes de Castilla. Ed. Cayetano Rosell. 2 vols. Madrid: B.A.E., 1875 y 1877.

Crónica del Halconero de Juan II. Ed. Juan de Mata Carriazo. Madrid: Espasa y Calpe, 1946.

JAEn, Didier T. Jobn II of Castile and the Grand Master Alvaro de Luna. Madrid: Castalia, 1978.

LoPEZ DE MendozA, IÑIGo, Marqués de Santillana. Obras completas. Ed. M. Kerkhof. Barcelona: Planeta, 1988.

MenA, JuAn DE. Laberinto de Fortuna. Ed. Louise Vasvari Fainberg. Madrid: Alhambra, 1976.

- Obra lírica. Ed. Miguel A. Pérez Priego. Madrid: Alhambra, 1979.

Pérez de Guzman, Fernan. Generaciones y semblanzas, en Crónicas de los Reyes de Castilla. Vol. II. 
Pérez Gomez, ANtonio. Romancero de don Alvaro de Luna. Valencia: La fonte que mana, 1953.

PISKorsKi, Wladimiro. Las Cortes de Castilla en el periodo de tránsito de la Edad Media a la Moderna 1188-1520. Barcelona: El Albir, 1977.

PuYmaigre, Le COMTE DE. La cour littéraire de don Juan II. Paris: Librairie A. Franck, 1873.

Round, Nicholas. The Greatest Man Uncrowned. London: Tamesis, 1986.

SuARez Fernandez, Luis. Los trastámaras de Castilla y Aragón en el siglo XV (1407-1474). Vol. XV de Historia de España. Ed. Ramón Menéndez Pidal. Madrid: Espasa y Calpe, 1970.

Vendrell Gallostra, Francisca. La corte literaria de Alfonso V de Aragón y tres poetas de la misma. Madrid: Tipografía de Archivos, 1933. 